\title{
Needs Analysis of the Application of Sport Science to Improve Physical Condition of Junior Tennis Athletes
}

\author{
Rina Ambar Dewanti*, Beltasar Tarigan, Dian Budiana \\ Department of Sport Education, Postgraduate School \\ Universitas Pendidikan Indonesia \\ Bandung, Indonesia \\ *rad jakarta@yahoo.com.au
}

\begin{abstract}
One of the main objectives of sport is to pursue optimal achievement. To develop progressions and measure this achievement requires the application of sport science. A key area of sports science in through strength and conditioning programming to help athletes to be stronger, faster, powerful, agile and have more resilience to endure physically and psychologically. The purpose of this study is to provide an overview for the need of applying sport science to improve the physical condition of junior tennis athletes. Data was collected from 11 (6 male and 5 female) players at Tennis Plus Bandung, aged 14 years. The methodology used in this research is a descriptive method to describe the comparison of data collected from a pre-determined battery of tests of the subjects' current physical condition and physical condition from researched normative data for male and female aged 14 years. Three instrument tests used were, namely: Push up for upper body strength, $20 \mathrm{~m}$ sprint for speed, and Bleep test for endurance. Results showed only 1 male subject was above the norm for speed. All subjects were below the norm for upper body strength, with 1 female and 3 male subjects recorded above the norm for endurance.
\end{abstract}

Keywords-analysis; application; sport science; strength conditioning; tennis junior

\section{INTRODUCTION}

Tennis is popular in all walks of life that is an enjoyable and exciting sport to play with many challenges for all ages such as; using hand eye coordination and physical athletic skills to get into position to hit a ball over a set net height. The goal to have the ball bounce within set lines including the added challenge of trying win a point by hitting the ball land in a position on the court your opponent is unable to successfully return the ball back over the net and land within the lines. There is no age limit, all age groups, male, female, children, adults, able bodied and people of all disabilities can enjoy playing tennis. Tennis can be played at any intensity and standard from beginners, social to professional. In terms of competitive tennis in Indonesia, tennis development appears to progress with the main agenda to play as many local, state, national or international tournaments (were possible) held over the calendar year. This has a focus direction on playing continuous intense competition for achievement and development. Therefore, players are required to be continuously preparing themselves for each match that has been included in the training program.

In this regard, training in local regions of Indonesia continue to be carried out in this format for development. This is highlighted by an increase of clubs and private coaching groups. The age of player participation is varied significantly from children to adults. The local associations and clubs have many structured age group categories being contested. Early age matches usually start from under 10 years, plus categories 11-12 years, 13-14 years, and so on through to adults. All categories early age, beginner, competitive players and parents show great enthusiasm in participation to test their abilities. However, it is unfortunate that many parents (of the children) and trainers appear to have impose their will for them to have a win focus, and less on participation, progressively developing their physical, skill and match strategy abilities for the game of tennis. A consequence of this, children in the 6-10 years age group receive training that is not in accordance with their chronological and development training age. One of the main objectives of sport is to pursue optimal achievement in competition. To achieve a desired performance, an athlete must have sound adequate abilities in physical, technical, psychological skills, and full understanding of match strategies in dealing with a tournament or matches. To achieve the desired performance to be able to win a match, there is a need for a well-structured progressive training plan to prepare the player for such situations to help achieve their optimal performance goals. However, there appears to be highly biased competition type of structure with training plans in local clubs and similar with less focus in player tennis skill of physical development. Based on the data below in this comparative study it displays an indication in the lack of physical development levels as compared to normative data in previously researched young age group tennis players. It can be identified this development component in local (provincial) Indonesian tennis training plans lack the application of sport science. Sport Science is a scientific application of the applied research principles and procedures used to assist athletes in improving their performance potential. Over the past 20 years, sport science has developed rapidly producing very comprehensive evidence-based research, understanding progressive strategies for programs to assist coaches in training plans to achieve optimal performance. 
This is a need to have better lines of communication between parents, coaches, trainers and the players to understand the importance of integrating sports science supporting tennis achievement. Sports science rationale highlights there are certain qualities and strategies all stakeholders in player development should be aware of for each individual athlete such as; athlete strengths and weaknesses, measuring the effectiveness of the training program, providing short-term goals, evaluating the athlete's health status, evaluating the athlete's mental skills, identifying the athlete's readiness in training and in matches. Strength and conditioning is one application of sport science, that can be implemented to increase the bio motor components of strength, speed, and endurance, especially during the physical growth stages of children aged 11-14 years. All Sports have certain dominant bio motor abilities as expressed by Bompa "most sport activities can be classified as having a predominant bio motor ability" [1]. Sports can be influenced by one or more bio motor abilities. This is supported by research conducted by Racinals, Bishop, et al [2]. That muscle strength seems to affect speed and endurance. The study indicates that the effect of strength on endurance can increase with resistance training for long distance runners or cyclists by producing improved performance far greater than just focusing on endurance training. Based on this data, it can be hypothesized that the forces associated with many bio motor components can affect performance in various sporting activities. Given strength has a positive training effect on other bio motor capabilities, strength must be considered as a dominant and important bio motor capability. From these findings children and adolescents need to be physically strong to maximize their sporting development, however certain guidelines should be put in place according to their development and training age. Training activities should be fun and vary regularly for up to 60 minutes or more. Applying strength training during childhood and adolescence can be the foundation for significant increases in muscle strength as they mature through their growth spurts. With proper guidance and direction, taking part in regular strength training programs can have beneficial effects on musculoskeletal health, body composition, cardiovascular risk factors, fitness performance and psychological well-being. Providing regular strength training to children can also have a good impact on fitness components related to skills of balance, speed, coordination, agility and reaction time. Therefore, the purpose of this study is to compare the researched physical components of strength, speed and endurance normative data of 14-year-old male and female tennis players and the test data findings from 14-year-old tennis players of Tennis Plus Bandung West Java.

\section{METHOD}

\section{A. Research Design}

The methods in this research used descriptive method. Descriptive method is used to make a factual description or description of the facts carried out in a study which can then be concluded. In this study a predetermined battery of physical component tests was conducted recording the test data and compared to the research based normative (norm.) data of the same test battery of 14-year-old tennis players.

\section{B. Participant}

This research was conducted at the Tennis Plus West Java Club. The population in this study were all tennis athletes for the club who actively participated in training camps and competitions. While the sample of research subjects used were boys and girls under 15 years of age. The sample selection technique uses purposive sampling technique. The subjects were athletes categorized in the third-tier level tennis athletes of West Java. A total of 11 subjects consisting of 6 males and 5 females freely accepted to participate in this research study.

\section{Instruments}

The test battery was conducted with the aim to measure the effectiveness of the application of sport science in improving physical conditions (strength, speed and endurance) of tennis athletes. The test instrument used is a standardized test instrument and in accordance with the criteria for measuring physical conditions (strength, speed and endurance). Before doing the tests, the subjects were advised not to be involved in activities that are too tiring within 3 days of the tests being conducted, with the aim to obtain maximal data recordings Three (3) instrument tests used were: Push up for upper body strength, 20m sprint for speed, and Bleep test for endurance. Before conducting the test battery recordings all subjects went through a 10-minute warm up via jogging and light mobility exercises. This was to elevate body temperature to mild perspiration level to allow the athlete to be prepared and confident to give the best efforts for each test conducted. Prior to testing the appropriate preparations were taken to set up the testing area for each test. Ensuring all equipment was functioning correctly, and strict measurement protocols were in place to conduct the tests. Including full explanation of the tests to the subjects.

\section{RESULT AND DISCUSSION}

Description of the data from the results of the study aims to provide a general description of the distribution of data distribution in the form of size distribution of frequency average, maximum value, minimum value, standard deviation, mode, median. The data results are recordings of: strength, speed and endurance. The description of the data for junior tennis athletes are presented in the table below.

TABLE I. DESCRIPTION OF RESEARCH RESULTS

\begin{tabular}{|l|l|l|l|}
\hline \multicolumn{1}{|c|}{ Analysis } & \multicolumn{1}{|c|}{ Speed } & \multicolumn{1}{c|}{ Strength } & \multicolumn{1}{c|}{ Endurance } \\
\hline Mean & 5.07 & 18.38 & 8.61 \\
\hline Median & 4.10 & 18 & 9.1 \\
\hline Modus & 4.71 & 20 & 6.2 \\
\hline Standard Deviation & 2.47 & 6.4 & 1.84 \\
\hline Min & 3.27 & 12 & 6.2 \\
\hline Max & 11.24 & 35 & 11.12 \\
\hline
\end{tabular}


The following are the physical condition norms compared to the raw data test results of the 11 subjects split into Male and Female tables.

TABLE II. NORMS OF PHYSICAL CONDITIONS AND PRELIMINARY TEST RESULTS FOR MALE ATHLETES

\begin{tabular}{|c|c|c|c|}
\hline \multirow{2}{*}{ Norma Boys 14} & Speed & Strength & Endurance \\
\hline & 3.36 & 36 & 46.81 \\
\hline \multirow{2}{*}{ No } & \multicolumn{3}{|c|}{ Research Result } \\
\hline & Speed & Strength & Endurance \\
\hline 1 & 3.62 & 25 & 49.3 \\
\hline 2 & 3.27 & 35 & 53.7 \\
\hline 3 & 4.28 & 20 & 47.7 \\
\hline 4 & 3.91 & 13 & 43.3 \\
\hline 5 & 3.8 & 18 & 46.2 \\
\hline 6 & 4.71 & 15 & 37.1 \\
\hline
\end{tabular}

TABLE III. NORMS OF PHYSICAL CONDITIONS AND PRELIMINARY TEST RESULTS FOR FEMALE ATHLETES

\begin{tabular}{|c|c|c|c|}
\hline Norma Girl 14 & Speed & Strength & Endurance \\
\hline & 3.4 & 28 & 46.64 \\
\hline \multirow[t]{2}{*}{ No } & \multicolumn{3}{|c|}{ Research Result } \\
\hline & Speed & Strength & Endurance \\
\hline 1 & 9.74 & 20 & 43.6 \\
\hline 2 & 11.24 & 22 & 47.4 \\
\hline 3 & 4.97 & 12 & 34.7 \\
\hline 4 & 4.76 & 15 & 35.7 \\
\hline 5 & 4.1 & 14 & 44.9 \\
\hline
\end{tabular}

Based on the research data above, for the physical condition of the test subjects, only 1 male was above the norm for speed of $0.09 \mathrm{sec}$. With the largest margin outside the norm is 1.35 sec. For the physical condition of muscle strength for male athletes, no subjects reached the strength norm. The average score in strength of all 6 male subjects was $42 \%$ outside the norm for strength. The physical condition of endurance for male subjects show 3 surpassed the norm.

No female subjects attained the physical condition of speed. A variance in speed was from $0.70 \mathrm{sec}$. to $7.34 \mathrm{sec}$. Outside the norm for speed. No female subjects attained the physical condition of muscle strength norms. The average score in strength of all 5 female subjects was $41 \%$ outside the norm for strength 1 female subject attained the physical condition of endurance. This study examines whether there is a need to apply sports science of strength and conditioning in training to improve physical conditions in young developing tennis players. The results show in the initial test results of physical conditions carried out by West Java Bandung Plus Tennis Club athletes were lacking in speed, strength and endurance as compared to normative data of research based 14-year-old tennis players. Therefore, it can be concluded the necessity to apply the sport science area of S \& C into the training program to improve physical conditions, for West Java Plus Tennis Club athletes. This could be one way to support the achievement of optimal athletic performance. Sports science is research-based studies for the application of scientific principles and techniques with the use of researched knowledge, technologies, case studies, and communication aiming to improve sports performance. The role and principles of sports science can be applied at nursery age children for improvement in acquiring physical literacy bio motor skills of physical conditions through to elite level sporting professionals. Sports science also studies anatomy, physiology, biomechanics, statistics, nutrition, psychology, measurement tests, performance history, sports medicine checking the quality of athletes' organs such as heart, lungs and muscles. From these studies it has identified and created the emergence of various types of training methods, statistical analysis strategies, athlete monitoring techniques, injury prevention and rehabilitation programming, advanced training facilities and infrastructure, to recommendations on various tactics and match strategies. The use of sport science in tennis can help an athlete to increase endurance, strength, speed, skills, recovery, energy systems, and so on. Tennis requires a variety of complex movement abilities and skills, such as acceleration, running fast, deceleration, stopping immediately, agility, jumping, reaching, rotating quickly, taking wide steps without losing body balance. This explains why tennis players are required to have good physical qualities in strength, endurance, flexibility, speed, agility and coordination of motion. These aspects are needed to be able to move and react to explore every corner of the court during the match. Tennis matches put a lot of stress on the anaerobic energy system requiring many repeated efforts of fast movement patterns and coordination while using a set of skills required to get into position and hit the ball back over the net and keeping the ball in play. These repeated movement efforts will cause "fatigue", which will directly affect the work of the heart, lungs, circulatory system, breathing, muscle work, and body joints. Therefore, it is very important for tennis players to have excellent physical conditioning. Through a well-programmed physical training process, these factors can be mastered. With excellent physical conditioning it can have a positive impact on mental fitness and psychological mindset, which ultimately affects directly the state of play for on court decision making and maintaining technical form. This is reinforced in several studies conducted related to the physical characteristics and demands that must be possessed in tennis. According to G. Smekal, S.P., etc, in the game of tennis a point generally lasts from 4 seconds to 20 seconds with a break of up to 25 seconds each time to serve [3]. Meanwhile, according to J. Fernandez, etc. the characteristics of the rally that occurs in the game of tennis can differ depending on the surface of the field used [4]. Rally on clay will last for 6 to 8 seconds, while the rally that occurs on the hard court usually lasts for 4 to 6 seconds. Thus, Kovacs, M.Sc states that the ratio of play: rest in tennis sports usually starts from 1:2 to $1: 5$ [5].

Tennis has some very dominant components of physical condition, namely: speed, strength and endurance. Speed is important for tennis players due to fast reaction movements in the first step at each stroke play of the game. An increase in 
speed even as little as a few one hundredth of a sec. over $2-5$ metres can change the player's ability of position in the state of play in a point of defending by getting into position earlier and change the state of play to an attacking position. Understanding this importance of speed ability, special speed development training is needed for tennis. However, speed for tennis is very different from speed in many other sports. In tennis, players react to a stimulus from the opponents' movements and strokes played including their own responses of getting to a ball, playing the stroke and recovering to be in position for the next the stroke of play. Therefore, players must focus to be well prepared and very consistent in every first step movement done in multiple directions. So, it can be said that the factors that influence speed at the initial steps in tennis include: core strength, maximum strength, power and reaction time.

An increase in strength can occur within the initial weeks of exercise for 5-8 weeks without having a noticeable change in muscle size. The increase in strength is caused by the contribution of neural firing factors. There are two adaptations that occur in increasing strength, namely intramuscular adaptation and intermuscular adaptation. Intramuscular adaptations include the number of motors that are recruited and the activation rate of those motor units [6]. While Intermuscular Adaptation refers to the improved coordination of muscle firing patterns. As exercise technique improves, the muscles will work more efficiently, and less energy is required to perform the exercise and the resistance can be increased [7]. To design a strength training program is to analyze the needs of athlete activities, consider several things, including: the main muscle groups used, the type of movement, the speed of movement and the place where injuries often occur. To be able to maximize the results obtained, the program must be specific to the sport and in accordance with the characteristics of the athlete.

The last component is endurance durability. Tennis matches require aerobic and anaerobic metabolism to sustain energy supply throughout the match. Anaerobic energy is used to supply energy as the athlete plays to gain points by doing explosive and fast movements. While aerobic energy is used to supply energy when a player breaks so that he can recover. Research by Bergeron, M. F. et al. and Kovacs states that tennis is aerobic sport due to the duration of matches which can last from 2-5 hours with relatively moderate mean heart rate values found during play [8,9]. Based on this it can be derived the importance to increase a player's ability in endurance with a very good aerobic capacity. It is suggested this can be done by completing long distance running exercises for 30 minutes or more, additional to structured interval training plans done 35 times per week

\section{CONCLUSIONS}

The results confirmed there were significant substandard performance data of physical condition in Speed, Strength and Endurance from both male and female subjects aged 14-yearold at Tennis Plus Bandung Club as compared to research based normative data of typical 14-year-old tennis players. It can be assumed if the players were able to achieve the norms of physical conditions as set from the research based normative data it may support improved physical abilities on court, to enable to player to play at their optimal best performance. Therefore, this study recommends the implementation of sports science $\mathrm{S} \& \mathrm{C}$ in exercise programming that aims to improve physical conditions to achieve the established physical norms as identified in this study of Speed, Strength and Endurance. The application of sport science in practice must adjust to the characteristics of tennis specifically with special attention to the characteristics of the chronological and training age of the players.

\section{REFERENCES}

[1] O.T. Bompa and G.G. Haff, Periodization; Theory and Methodology of Training, Fifth Edition, Europe: Human Kinetics, 2009.

[2] S. Racinais, D. Bishop, R. Denis, G. Lattier, A. Mendez-Villaneuva, S. Perrey, Muscle deoxygenation and neural drive to the muscle during repeated sprint cycling. Medicine \& Science in Sports \& Exercise. 2007 Feb 1;39(2):268-74

[3] G. Smekal, S.P. von Duvillard, C. Rihacek, R. Pokan, P. Hofmann, R Baron, H.Tschan, and N. Bachl, "A physiological profile of tennis match play," Medicine and Science in Sports and Exercise. 2001 Jun;33(6):999-1005.

[4] J. Fernandez-Fernandez, V. Kinner, and A. Ferrauti, "The physiological demands of hitting and running in tennis on different surfaces," Journal of Strength and Conditioning Res 2010, 24(12): 3255-3264.

[5] M.S. Kovacs, Tennis physiology: training the competitive athletes, Sports Medicine, 2007 37(3), 189-198.

[6] J.M. Cissik, The basics of strength training. New York: The McGrawHill Companies, Inc., 2001.

[7] R.T. Harris and G. Dudley, Neuromuscular anatomy and adaptations to conditioning. In: Essentials of Strength Training and Conditioning. T. R.Baechle and R. Earle (Eds.) Champaign, IL: Human Kinetics, 2000.

[8] M.F. Bergeron, C. M. Maresh, W. J. Kraemer, A. Abraham, B. Conroy, and C. Gabaree, Tennis: a physiological profile during match play. Int J Sport Med. 12:474-479, 1991.

[9] M.S. Kovacs, Applied physiology of tennis performance. British Journal of Sports Medicine. 40:381-386, 2006 